bioRxiv preprint doi: https://doi.org/10.1101/2022.02.24.481226; this version posted February $26,2022$. The copyright holder for this preprint (which was not certified by peer review) is the author/funder, who has granted bioRxiv a license to display the preprint in perpetuity. It is made available under aCC-BY-NC-ND 4.0 International license.

\title{
Three Mutations Convert the Selectivity of a Protein Sensor From Nicotinic Agonists to S-Methadone For Use in Cells, Organelles, and Biofluids
}

Anand K. Muthusamy ${ }^{1,2}$, Charlene H. Kim¹, Scott C. Virgil2, Hailey J. Knox², Jonathan S. Marvin ${ }^{3}$, Aaron L. Nichols ${ }^{1}$, Bruce N. Cohen ${ }^{1}$, Dennis A. Dougherty², Loren L. Looger ${ }^{4}$, and Henry A. Lester ${ }^{* 1}$

1'Division of Biology and Biological Engineering, California Institute of Technology, Pasadena, CA 91106 2Division of Chemistry and Chemical Engineering, California Institute of Technology, Pasadena, CA 91106 3Howard Hughes Medical Institute, Janelia Research Campus, Ashburn, VA 20147 ${ }^{4}$ Howard Hughes Medical Institute, University of California, San Diego, San Diego, California, 92093 ${ }^{*}$ Corresponding author

\begin{abstract}
We report a reagentless, intensity-based S-methadone fluorescent sensor, iS-methadoneSnFR, consisting of a circularly permuted GFP inserted within the sequence of a mutated bacterial periplasmic binding protein (PBP). We used directed evolution to convert a previously reported nicotine-binding PBP to a selective S-methadone-binding sensor, via three mutations in the PBP's second shell and hinge regions. iS-methadoneSnFR displays sensitivity across the pharmacologically relevant range and selectivity against endogenous analytes and other opioids. Robust iSmethadoneSnFR responses in human sweat and saliva and mouse serum enable diagnostic uses. Genetic encoding and imaging in mammalian demonstrated the acid trapping of S-methadone in the Golgi apparatus where opioid receptors can signal. This work shows a straightforward strategy in adapting existing PBPs to serve real-time applications ranging from subcellular to personal pharmacokinetics.
\end{abstract}

\section{Main text:}

We report the first selective real-time fluorescent biosensor for a small molecule opioid, "intensity-based S-methadone sensing fluorescent reporter" or "iS-methadoneSnFR" (Figure 1). To employ the indicator for quantitative dynamic opioid measurements in cells and biofluids, we engineered iS-methadoneSnFR to meet necessary criteria: (1) sensitivity in the pharmacological range, (2) selectivity against endogenous molecules, (3) selectivity against exogenous drugs, including those of the same drug class, (4) photostability for the duration of measurements, (5) physical stability outside cells, and (6) reversible binding with $\sim$ second resolution.

The risk of opioid-use disorder and death by overdose has increased alongside the worldwide access to highly potent opioid agonists ${ }^{1}$. Nevertheless, opioids remain essential analgesics. Since the 1960s, methadone maintenance therapy (MMT) has served to reduce harm from opioid addiction ${ }^{2,3}$. MMT relies on pharmacokinetics: oral methadone's onset is slower than that of injected or inhaled $\mu$-opioids, and its effects last much longer due to $\mathrm{a} \sim 24 \mathrm{~h}$ half-life ${ }^{4}$. Therefore, despite acting as a $\mu$-opioid agonist, methadone staves off withdrawal symptoms without producing the euphoria associated with other agonists ${ }^{4}$. However, interindividual variability in the metabolism of methadone, partiality due to polymorphisms in cytochrome P450 isotypes ${ }^{5,6}$, can lead to therapeutic failures ${ }^{7}$. Methadone is clinically administered as the racemate and measuring either enantiomer is suitable for therapeutic drug monitoring ${ }^{8}$. Drug metabolism is conventionally addressed by blood draw, but this method is laborious, invasive, and restricted to the clinic. An optimal methadone readout would enable personalized dosing regimens, by producing real-time tracking of [methadone] in biological fluids and facilitating tapering from potent opioids. Within a subject, opioid pharmacokinetics also varies at the level of intracellular compartments to produce acid trapping and

(b)

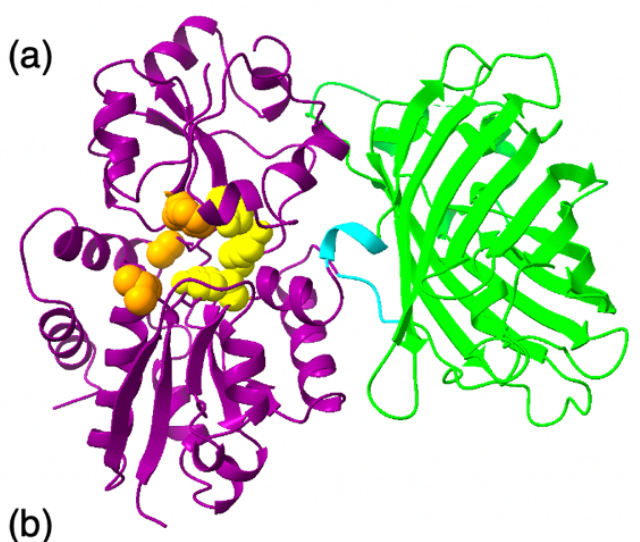

Unbound/inactive
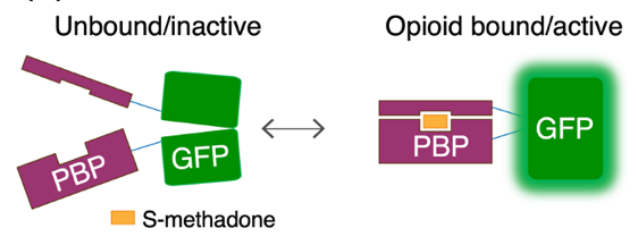

Figure 1: (a) Crystal structure of iNicSnFR3a (PDB: 7S7T) mutated in silico to iS-methadoneSnFR (mutations shown in orange spheres). All but one putative cation- $\pi$ residue in iNicSnFR3a were maintained in iS-methadoneSnFR's binding pocket (critical residues Y65, Y357, and Y460 shown as yellow spheres). (b) Biosensor mechanism: in the unbound state, GFP's chromophore has a poor environment for fluorescence. The PBP binds S-methadone with a "Venus flytrap" conformational change, increasing the brightness of the GFP chromophore. diverse interactions with receptors including chaperoning and activation ${ }^{9,10,11}$. In both cases, a sensor with in situ readout and $\sim$ second resolution is required. 

available under aCC-BY-NC-ND 4.0 International license.

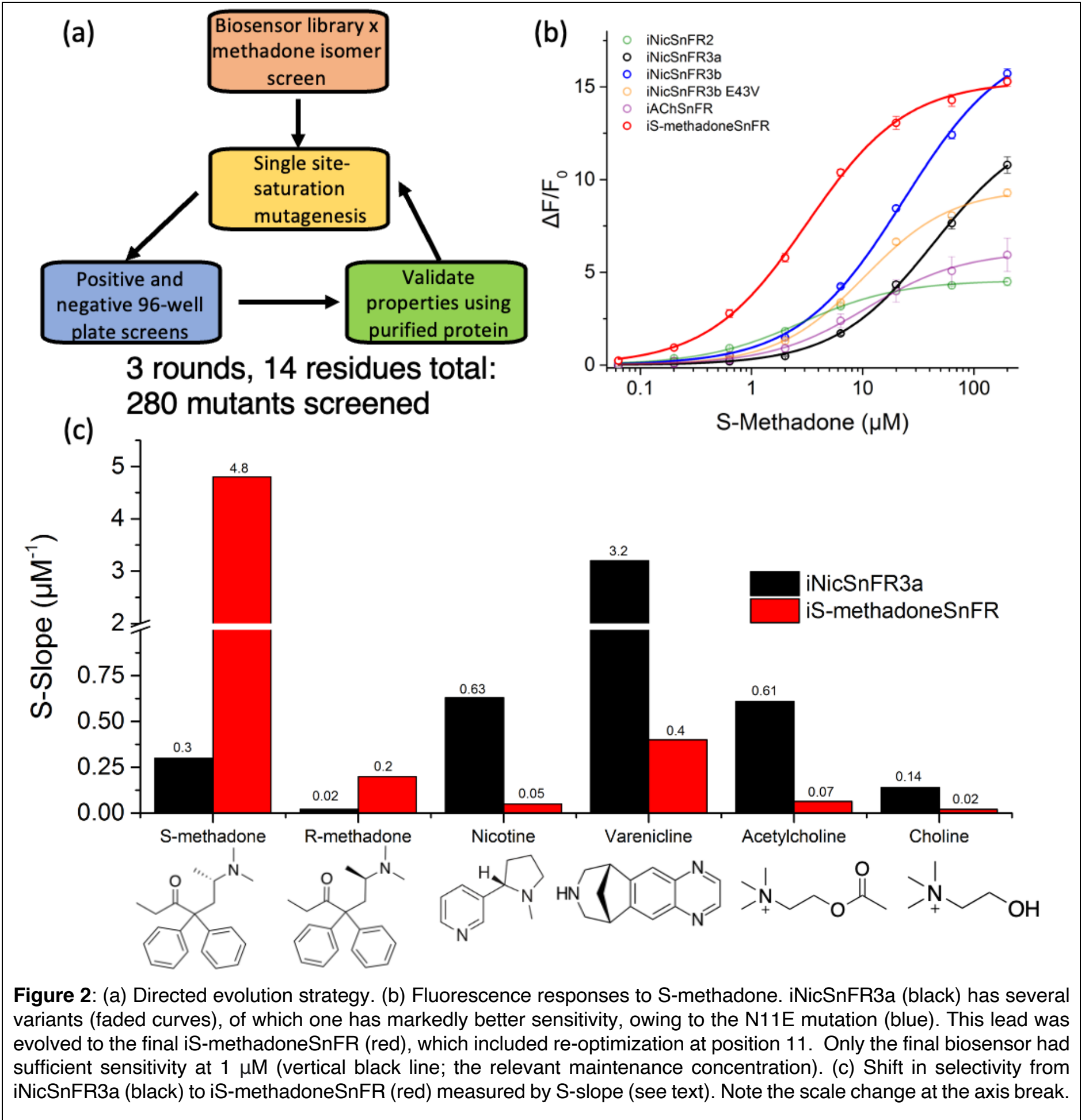

In a pioneering de novo protein design campaign for an opioid sensor, binding of fentanyl produced a conformational switch in a transcription factor ${ }^{12}$ but required a cellular readout and hours-to-days temporal resolution. We hypothesized that all criteria could be satisfied by a single-chain sensor comprising a mutated bacterial periplasmic binding protein (PBP), a variant of the choline-binding protein OpuBC from Thermoanaerobacter sp513, interrupted by a circularly permuted GFP (cpGFP)(Figure 1) ${ }^{13,14,15}$. The cpGFP insertion approach has also been used in $\mathrm{Ca}^{2+}$ sensors (the GCaMP series) and in neurotransmitter sensors ${ }^{13,16}$. Our strategy consisted of (1) screening each methadone enantiomer against a previously reported nicotine biosensor, iNicSnFR3a, and its variants ${ }^{14}$ and (2) iterative site-saturation mutagenesis to select for Smethadone and against cholinergic ligands (Figure 2a). We performed chiral resolution on racemic methadone to isolate (+)-S-methadone and (-)-R-methadone (assigned by optical rotation ${ }^{17}$ ) with analytical purity and $99 \%$ enantiomeric excess (Figure S1). While there is no structural homology or pharmacological overlap between nicotinic and $\mu$-opioid receptors, several variants of nicotinic drug biosensors displayed weak fluorescence 

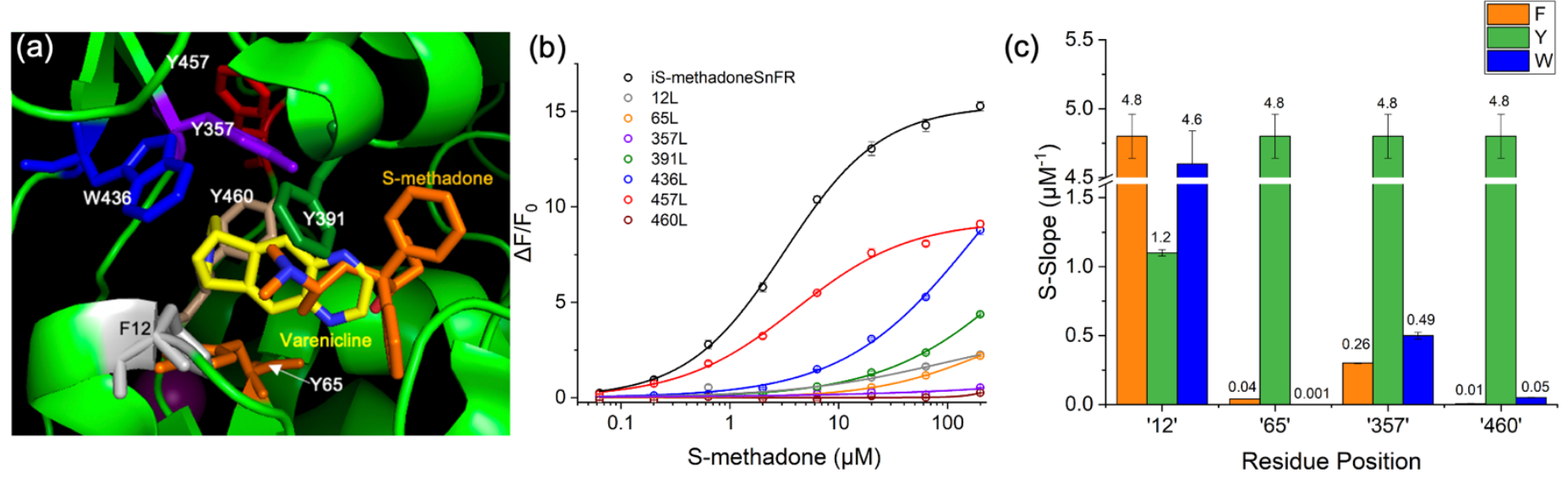

Figure 3: (a) PDB: 7S7T (iNicSnFR3a, varenicline bound) showing cation- $\pi$ interactions with Y65 and Y357. Smethadone was docked into 7S7T. (b) Fluorescence dose-response relations of cation- $\pi$ residue Leu mutants. (c) Aromatic side-chain screen through critical positions identified in (b) with resulting S-slope. Note the break in y-axis.

responses to S-methadone (Figure 2b). Although the PBP had no enantioselective pressure for binding its achiral ligand choline, all variants screened to date displayed enantioselectivity for S-methadone (Figure S2). Dose-response relations were fit to the Hill equation to determine an $\mathrm{EC}_{50}$ and $\Delta \mathrm{F}_{\mathrm{max}} / \mathrm{F}_{0}$. In the linear portion of the dose-response relation we define the increase in fluorescence per micromolar, "S-slope", as a metric of biosensor sensitivity: $\left(\Delta\left(\mathrm{F} / \mathrm{F}_{0}\right) /\left(\Delta[\right.\right.$ ligand] $)$ at [drug] $\left.<<\mathrm{EC}_{50}{ }^{18}\right)$. For a Hill coefficient of $\sim 1.0$, the $\mathrm{S}$-slope equals the ratio $\left(\Delta \mathrm{F}_{\max } / \mathrm{F}_{0}\right) / \mathrm{EC}_{50}$. A variant of iNicSnFR3a, iNicSnFR3b, provided the largest dynamic range for both $S-$ methadone and R-methadone (Figure S2) and served as the input to several rounds of directed evolution.

We selected for both an increase in sensitivity to S-methadone and a decrease in sensitivity to nicotinic ligands. We chose mutation sites based on a crystal structure of iNicSnFR1 (PDB: 6EFR) and directed evolution of iNicSnFR3a ${ }^{14}$. The resulting sensor displayed a $\sim 16$-fold improvement in sensitivity over iNicSnFR3a; $\Delta \mathrm{F} / \mathrm{F}_{0}$ increased to $3.76 \pm 0.16$ at $1 \mu \mathrm{M}$, the representative plasma maintenance concentration ${ }^{8}$ (Figure 2b). Notably, iS-methadoneSnFR displayed sensitivity to S-methadone that exceeded the sensitivity for any of the original cholinergic ligands and displayed a marked shift in ligand selectivity (Figure 2c). iS-methadoneSnFR displayed near-zero response for physiologically or pharmacologically relevant steady-state acetylcholine (ACh), choline, varenicline, and nicotine concentrations $\left(\sim 1 \mu \mathrm{M}, 10\right.$ to $20 \mu \mathrm{M}^{19}, 0$ to $100 \mathrm{nM}^{20}$ and $\sim 25$ to $\sim 500 \mathrm{nM}$, respectively21 (Figure 4a below)).

We characterized iS-methadoneSnFR's binding using docking and biochemical studies. Although only three mutations were required to generate iS-methadoneSnFR from iNicSnFR3a/3b, advantageous mutations were rare: $\sim 1 \%$ of all mutations screened were accepted as improvements. Docking S-methadone into recently reported structures of liganded iNicSnFR3a ${ }^{22}$ showed that the $\mathrm{N}$-methyl groups of S-methadone lie 4.6 and 5.5 $\AA$ from the aromatic groups of $\mathrm{Y} 357$ and $\mathrm{Y} 65$, respectively (slightly greater than the distance from the beta carbons of varenicline to these two groups). In the initial round of mutations, most sites yielded no improvement, except for a W436F mutation spatially near Y65 and Y357 (Figure S3). We previously reported nicotine and varenicline making cation- $\pi$ interactions with Y65 and Y357 in iNicSnFR3a (PDB: 7S7T, 7S7U, respectively) ${ }^{22}$. Each nicotinic ligand bears a protonated nitrogen lying midway on the axis of the aromatic centroids of Y65 and Y357 (Figure 3a). In the subsequent round, second-shell mutation N11V created additional volume next to F12, in the second shell. Finally, the third round yielded L490A, allowing for greater flexibility in the hinging of the PBP.

Scanning Leu mutagenesis through the binding pocket aromatic residues showed the primacy of Y65, Y357, F12, and Y460 (Figure 3b). An aromatic side-chain screen across these four positions revealed a necessity of Tyr in the $1^{\text {st }}$ shell positions Y65, Y357, and Y460 (Figure 3c). Substituting a noncanonical side chain, O-methyltyrosine, yielded a near-null biosensor at residue 65 but not at 12 (Figure S4). These data suggest that S-methadone's amine directly interacts with the $1^{\text {st }}$ shell residues, as for nicotinic drugs, and the phenolic $-\mathrm{OH}$ is necessary for hydrogen bonding. The three accepted mutations represent a $94 \AA^{3}$ reduction in van der Waals' volume, comparable to the $132 \AA^{3}$ increase in ligand volume from varenicline to methadone, as though the accepted mutations allowed S-methadone better access to aromatic residues critical to binding both classes of drugs. Therefore, the PBP has an aromatic binding pocket for protonated amines, and other regions of the binding site can be tuned to accommodate the remainder of the ligand's steric bulk and functional groups. 


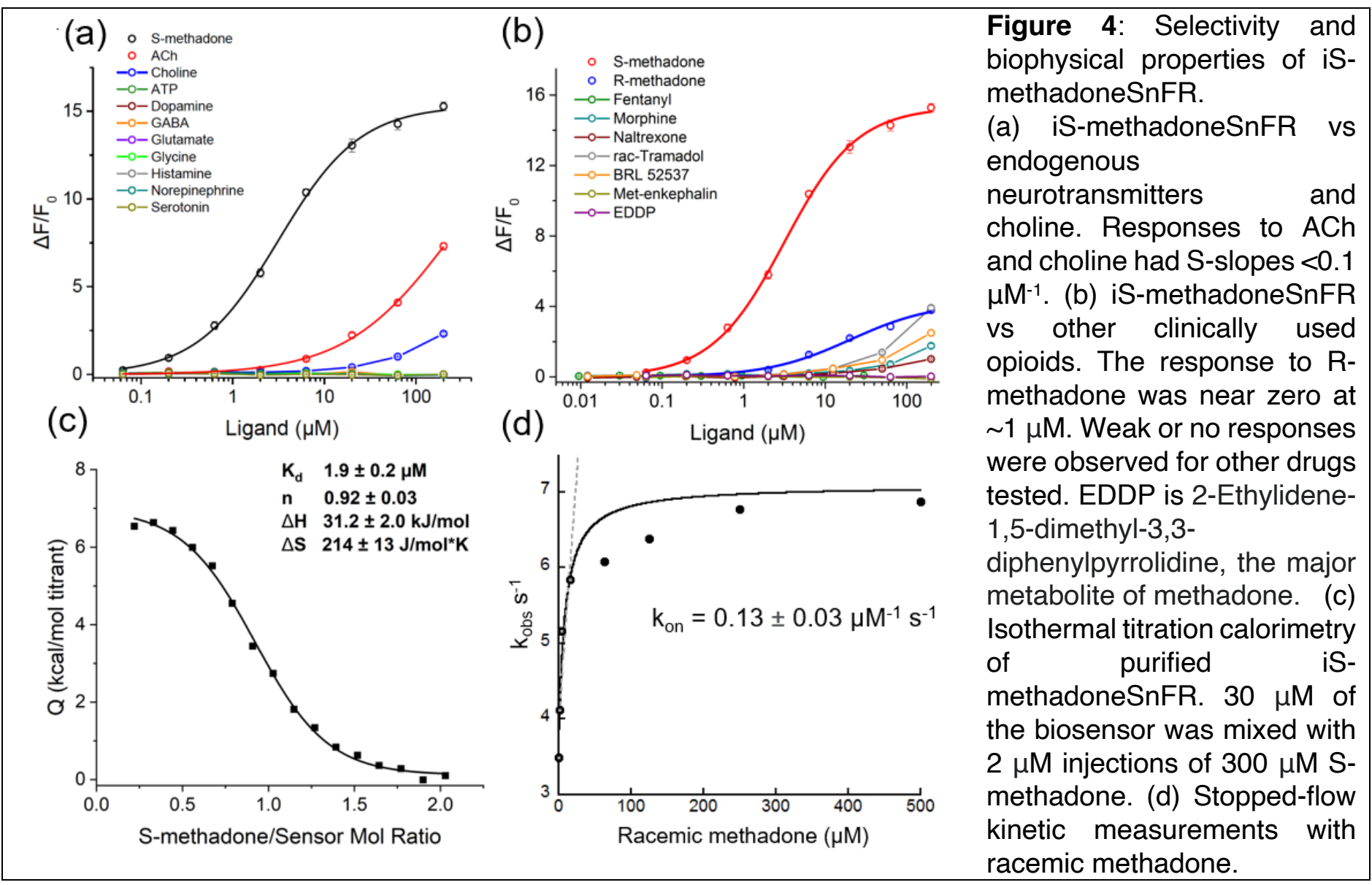

iS-methadoneSnFR satisfied our sensitivity, selectivity, and biophysical criteria for a useful biosensor. Fluorescence dose-response relations showed an excellent dynamic range, $\Delta F_{\max } / F_{0}$ of $15.3 \pm 0.2$, and an $E C_{50}$, $3.2 \pm 0.2 \mu \mathrm{M}$, near the relevant plasma concentrations for maintenance therapy ${ }^{8}$. Isothermal titration calorimetry (ITC) determined a $\mathrm{K}_{d}$ of $1.9 \pm 0.2 \mu \mathrm{M}$, in good agreement with the fluorescence $\mathrm{EC}_{50}$ (Figure 4c). ITC also demonstrated a single binding site (stoichiometry $=0.92$ ) with an entropically-driven conformational change. iSmethadoneSnFR had little or no response (S-slope $<0.1 \mu \mathrm{M}^{-1}$ ) to other neurotransmitters (Figure 4a) and other opioids (Figure 4b). The S-slope for S-methadone was $20 x$ that for R-methadone. When we added Rmethadone to S-methadone, fluorescence was modestly elevated at lower [S-methadone], but all responses converged at the $\Delta \mathrm{F}_{\max } / \mathrm{F}_{0}$ for S-methadone alone (Figure S5). 1-second stopped flow kinetics were obtained using racemic methadone (Figure S4) and determined an apparent $\mathrm{k}_{\text {on }}$ of $0.13 \mu \mathrm{MM}^{-1} \mathrm{~s}^{-1}$ (Figure 4d). The final 10 $\mathrm{ms}$ of the 1 second stopped-flow traces were fitted by a Hill equation with $\mathrm{EC}_{50} \sim 8 \mu \mathrm{M}$ (Figure S6) for the racemate, which was approximately double the $\mathrm{EC}_{50}$ for $\mathrm{S}$-methadone alone (as expected if the binding strongly favors the S-enantiomer).

Therapeutic use of opioids would be improved by quantitative, real-time, minimally invasive or noninvasive measurements in sweat, saliva, and interstitial fluid. ${ }^{23,24}$. The selectivity and high aqueous solubility of iS-methadoneSnFR enable its use in such applications. We tested the biosensor in PBS:biofluid samples and found robust responses in the pharmacologically relevant concentration range (Figure 5). iS-methadoneSnFR, like all GFP-based biosensors, displays smaller responses at $\mathrm{pH}<\sim 7$ (Figure S7). Because biofluids, particularly sweat, have variable and/or acidic $\mathrm{pH}, 3 \times \mathrm{PBS}$ was used to partially buffer a mixture with the biofluid. Still, the response at $1 \mu \mathrm{M}$ and below in the biofluids provide at least $\sim 200 \%$ dynamic range.

At the subcellular level, membrane-permeant weakly basic opioid drugs, but not impermeant derivatives or endogenous opioid peptides, enter the endoplasmic reticulum, and can act as pharmacological chaperones, altering the folding and trafficking of their receptors ${ }^{10}$. Opioid drugs also activate their receptors in endosomes and the Golgi apparatus ${ }^{11}$. We targeted iS-methadoneSnFR to the plasma membrane, endoplasmic reticulum, and Golgi apparatus of HeLa using targeting sequences (Figure 6a). We applied pulses of S-methadone (0 to $250 \mathrm{nM}$ in $50 \mathrm{nM}$ steps) to measure the linear portion of the dose-response relation (S-slope) in widefield imaging (Figure S8). The results indicate that ample S-methadone is available in the ER for potential chaperoning. The Golgi showed the largest S-slope among the three compartments (1.7x that of PM), despite having the lowest 
bioRxiv preprint doi: https://doi.org/10.1101/2022.02.24.481226; this version posted February $26,2022$. The copyright holder for this preprint (which was not certified by peer review) is the author/funder, who has granted bioRxiv a license to display the preprint in perpetuity. It is made available under aCC-BY-NC-ND 4.0 International license.

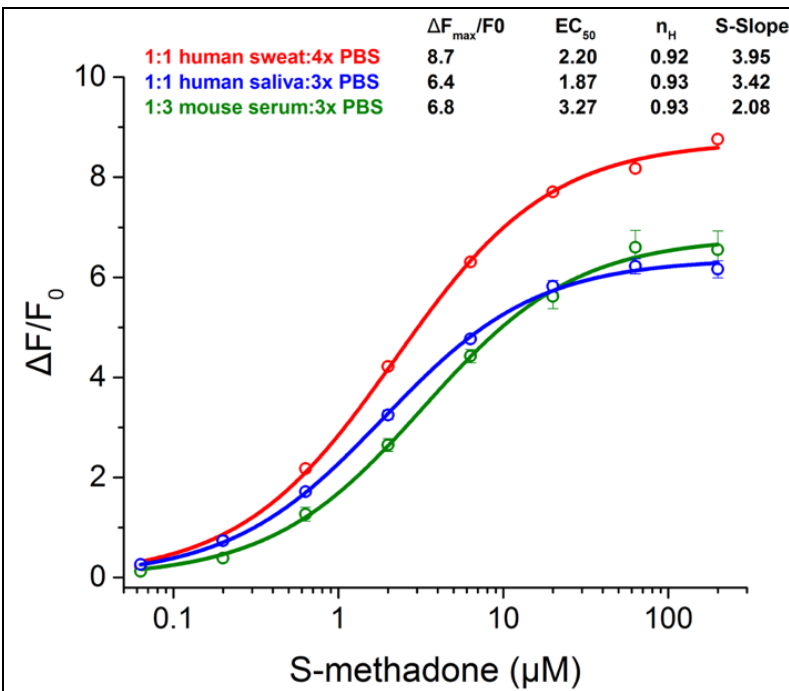

Figure 5: iS-methadoneSnFR dose-response relation in biofluids. 1:1 mixture of drug/biosensor in 3x PBS pH 7.4 with human sweat, human saliva, and 1:3 mixture with mouse serum (no $\mathrm{pH}$ adjustment of any biofluid).
$\mathrm{pH}$ (Figure 6b). After correcting the S-slope for $\mathrm{pH}$ dependence, we find an accumulation factor of $2.9 x$ to $4.4 x$ across the Golgi pH range of 6.3 to $6.8^{25}$ (Figure S8). Accumulation of opioids such as methadone in acidic compartments $^{26}$ may lead to intensified G-protein coupled signaling. We also validated iS-methadoneSnFR for timeresolved measurements in primary hippocampal neurons, encouraging mechanistic studies in tissues and in vivo (Figure S9).

Along with other sensors of opioid signaling ${ }^{11,27}$, this study establishes the first genetically encoded fluorescent protein biosensor for an opioid drug, enabling real-time quantification. Furthermore, the enantioselectivity encourages biosensor development to investigate "chiral switching" of other drugs where a single enantiomer substitutes a clinically used racemate ${ }^{28}$. One enantiomer may serve previously unstudied indications. For example, S-methadone is now under clinical investigation as a rapidly acting antidepressant via non-opioid mechanism(s) ${ }^{29}$. The directed evolution results demonstrate that the nicotinic PBP may be converted to detect non-nicotinic small molecule amines by tuning residues around the aromatic $1^{\text {st }}$ shell. Drug biosensors in vivo can monitor drug concentration near receptors during administration by the experimenter or the subject, a common manipulation for studying mechanisms of reward, analgesia, and drug abuse. To meet immediate needs for diagnostics, iS-methadoneSnFR can also provide in situ readouts in the laboratory or home.

(a)
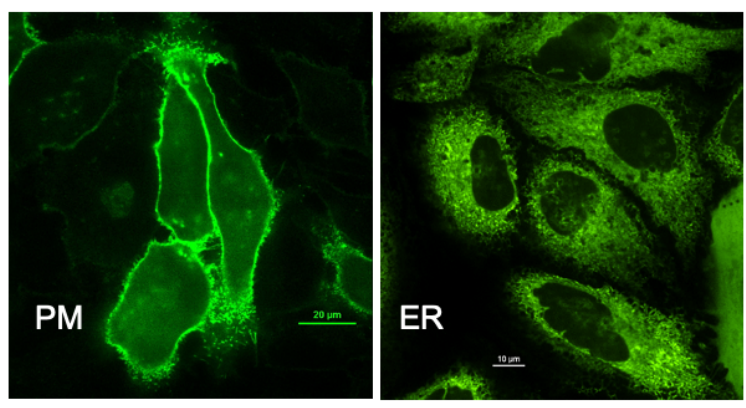

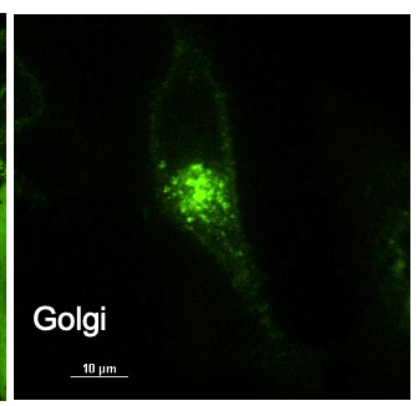

(b)

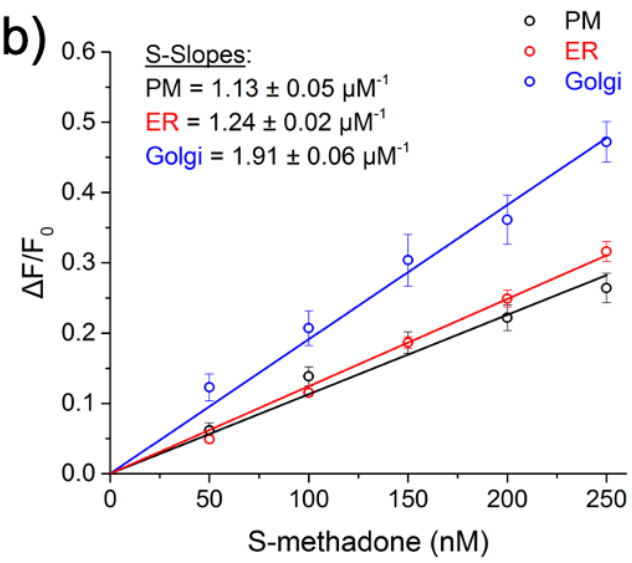

Figure 6: (a) Spinning disc confocal imaging of HeLa cells transfected with iS-methadoneSnFR_PM, ER, and_Golgi (470 nm excitation, $535 \mathrm{~nm}$ emission, 100x 1.4 NA objective). Scale bar $=10$ microns. (b) S-slope plotted for each organelle response at 0-250 $\mathrm{nM}$ S-methadone. Points are average responses to a 1 min pulse of [S-methadone]. PM n $=11$ cells; ER $n=10$; Golgi $n=11$.

Disclosure: AKM, HAL, LLL, and JSM have filed a patent that includes iS-methadoneSnFR.

Acknowledgements: The Caltech Center for Catalysis and Chemical Synthesis supported by the Beckman Institute supported the chiral resolution work. The CLOVER Center at Caltech and Gradinaru lab provided plasmids and advice for AAV production. Andres Collazo and Giada Spigolon manage the Biological Imaging Facility supported by the Beckman Institute and advised on confocal imaging. The Proteome Exploration Laboratory was supported by NIH OD010788, NIH OD020013, the Betty and Gordon Moore Foundation through grant GBMF775 and the Beckman Institute at Caltech. Wei Gao, You Yu, and Heather Lukas gathered human sweat. We thank Luke Lavis for contributive discussions. We thank Aiden Aceves and Stephen Mayo for advice on docking, Theodore Chin for assistance in cloning, and Purnima Deshpande for excellent lab management. 
bioRxiv preprint doi: https://doi.org/10.1101/2022.02.24.481226; this version posted February $26,2022$. The copyright holder for this preprint (which was not certified by peer review) is the author/funder, who has granted bioRxiv a license to display the preprint in perpetuity. It is made available under aCC-BY-NC-ND 4.0 International license.

\section{References:}

(1) Althoff, K. N.; Leifheit, K. M.; Park, J. N.; Chandran, A.; Sherman, S. G. Opioid-Related Overdose Mortality in the Era of Fentanyl: Monitoring a Shifting Epidemic by Person, Place, and Time. Drug and Alcohol Dependence 2020, 216, 108321. https://doi.org/10.1016/j.drugalcdep.2020.108321.

(2) Dole, V. P. A Medical Treatment for Diacetylmorphine (Heroin) Addiction. 1965, 198 (8), 646-650. https://doi.org/10.1001/jama.1965.03090080008002.

(3) Dole, V. P. Methadone Maintenance Treatment for 25,000 Heroin Addicts. JAMA 1971, 215 (7), $1131-$ 1134. https://doi.org/10.1001/jama.1971.03180200055012.

(4) Handbook of Methadone Prescribing and Buprenorphine Therapy, 1st ed.; Cruciani, R., Knotkova, H., Eds.; Springer: New York, New York.

(5) Eap, C. B.; Buclin, T.; Baumann, P. Interindividual Variability of the Clinical Pharmacokinetics of Methadone: Implications for the Treatment of Opioid Dependence. Clinical Pharmacokinetics 2002, 41 (14), 1153-1193. https://doi.org/10.2165/00003088-200241140-00003.

(6) Li, Y.; Kantelip, J.-P.; Schieveen, P. G.; Davani, S. Interindividual Variability of Methadone Response: Impact of Genetic Polymorphism. Mol Diag Ther 2008, 12 (2), 109-124. https://doi.org/10.1007/BF03256276.

(7) Nilsson, M.-I.; Grönbladh, L.; Widerlöv, E.; Anggård, E. Pharmacokinetics of Methadone in Methadone Maintenance Treatment: Characterization of Therapeutic Failures. Eur J Clin Pharmacol 1983, 25 (4), 497-501. https://doi.org/10.1007/BF00542117.

(8) Foster, D. J. R.; Somogyi, A. A.; Dyer, K. R.; White, J. M.; Bochner, F. Steady-State Pharmacokinetics of (R)- and (S)-Methadone in Methadone Maintenance Patients: Pharmacokinetics of (R)- and (S)Methadone. British Journal of Clinical Pharmacology 2000, 50 (5), 427-440. https://doi.org/10.1046/j.1365-2125.2000.00272.x.

(9) Lester, H. A.; Miwa, J. M.; Srinivasan, R. Psychiatric Drugs Bind to Classical Targets Within Early Exocytotic Pathways: Therapeutic Effects. Biological Psychiatry 2012, 72 (11), 907-915. https://doi.org/10.1016/j.biopsych.2012.05.020.

(10) Petäjä-Repo, U. E.; Lackman, J. J. Targeting Opioid Receptors with Pharmacological Chaperones. Pharmacological Research 2014, 83, 52-62. https://doi.org/10.1016/j.phrs.2013.12.001.

(11) Stoeber, M.; Jullié, D.; Lobingier, B. T.; Laeremans, T.; Steyaert, J.; Schiller, P. W.; Manglik, A.; von Zastrow, M. A Genetically Encoded Biosensor Reveals Location Bias of Opioid Drug Action. Neuron 2018, 98 (5), 963-976.e5. https://doi.org/10.1016/j.neuron.2018.04.021.

(12) Bick, M. J.; Greisen, P. J.; Morey, K. J.; Antunes, M. S.; La, D.; Sankaran, B.; Reymond, L.; Johnsson, K.; Medford, J. I.; Baker, D. Computational Design of Environmental Sensors for the Potent Opioid Fentanyl. eLife 2017, 6, e28909. https://doi.org/10.7554/eLife.28909.

(13) Marvin, J. S.; Borghuis, B. G.; Tian, L.; Cichon, J.; Harnett, M. T.; Akerboom, J.; Gordus, A.; Renninger, S. L.; Chen, T.-W.; Bargmann, C. I.; Orger, M. B.; Schreiter, E. R.; Demb, J. B.; Gan, W.-B.; Hires, S. A.; Looger, L. L. An Optimized Fluorescent Probe for Visualizing Glutamate Neurotransmission. Nat Methods 2013, 10 (2), 162-170. https://doi.org/10.1038/nmeth.2333.

(14) Shivange, A. V.; Borden, P. M.; Muthusamy, A. K.; Nichols, A. L.; Bera, K.; Bao, H.; Bishara, I.; Jeon, J.; Mulcahy, M. J.; Cohen, B.; O’Riordan, S. L.; Kim, C.; Dougherty, D. A.; Chapman, E. R.; Marvin, J. S.; Looger, L. L.; Lester, H. A. Determining the Pharmacokinetics of Nicotinic Drugs in the Endoplasmic Reticulum Using Biosensors. Journal of General Physiology 2019, 151 (6), 738-757. https://doi.org/10.1085/jgp.201812201.

(15) Borden, P. M.; Zhang, P.; Shivange, A. V.; Marvin, J. S.; Cichon, J.; Dan, C.; Podgorski, K.; Figueiredo, A.; Novak, O.; Tanimoto, M.; Shigetomi, E.; Lobas, M. A.; Kim, H.; Zhu, P. K.; Zhang, Y.; Zheng, W. S.; Fan, C.; Wang, G.; Xiang, B.; Gan, L.; Zhang, G.-X.; Guo, K.; Lin, L.; Cai, Y.; Yee, A. G.; Aggarwal, A.; Ford, C. P.; Rees, D. C.; Dietrich, D.; Khakh, B. S.; Dittman, J. S.; Gan, W.-B.; Koyama, M.; Jayaraman, V.; Cheer, J. F.; Lester, H. A.; Zhu, J. J.; Looger, L. L. A Fast Genetically Encoded Fluorescent Sensor for Faithful in Vivo Acetylcholine Detection in Mice, Fish, Worms and Flies. BioRxiv 2020.

https://doi.org/10.1101/2020.02.07.939504.

(16) Tian, L.; Hires, S. A.; Mao, T.; Huber, D.; Chiappe, M. E.; Chalasani, S. H.; Petreanu, L.; Akerboom, J.; McKinney, S. A.; Schreiter, E. R.; Bargmann, C. I.; Jayaraman, V.; Svoboda, K.; Looger, L. L. Imaging Neural Activity in Worms, Flies and Mice with Improved GCaMP Calcium Indicators. Nat Methods 2009, 6 (12), 875-881. https://doi.org/10.1038/nmeth.1398. 
(17) Larsen, A. A.; Tullar, B. F.; Elpern, B.; Buck, J. S. The Resolution of Methadone and Related Compounds. J. Am. Chem. Soc. 1948, 70 (12), 4194-4197. https://doi.org/10.1021/ja01192a065.

(18) Bera, K.; Kamajaya, A.; Shivange, A. V.; Muthusamy, A. K.; Nichols, A. L.; Borden, P. M.; Grant, S.; Jeon, J.; Lin, E.; Bishara, I.; Chin, T. M.; Cohen, B. N.; Kim, C. H.; Unger, E. K.; Tian, L.; Marvin, J. S.; Looger, L. L.; Lester, H. A. Biosensors Show the Pharmacokinetics of S-Ketamine in the Endoplasmic Reticulum. Front. Cell. Neurosci. 2019, 13, 499. https://doi.org/10.3389/fncel.2019.00499.

(19) Zeisel, S. H.; Epstein, M. F.; Wurtman, R. J. Elevated Choline Concentration in Neonatal Plasma. Life Sciences 1980, 26 (21), 1827-1831. https://doi.org/10.1016/0024-3205(80)90585-8.

(20) Faessel, H. M.; Obach, R. S.; Rollema, H.; Ravva, P.; Williams, K. E.; Burstein, A. H. A Review of the Clinical Pharmacokinetics and Pharmacodynamics of Varenicline for Smoking Cessation: Clinical Pharmacokinetics 2010, 49 (12), 799-816. https://doi.org/10.2165/11537850-000000000-00000.

(21) Russell, M. A.; Jarvis, M.; Iyer, R.; Feyerabend, C. Relation of Nicotine Yield of Cigarettes to Blood Nicotine Concentrations in Smokers. BMJ 1980, 280 (6219), 972-976.

https://doi.org/10.1136/bmj.280.6219.972.

(22) Nichols, A. L.; Blumenfeld, Z.; Fan, C.; Luebbert, L.; Blom, A. E. M.; Cohen, B. N.; Marvin, J. S.; Borden, P. M.; Kim, C. H.; Muthusamy, A. K.; Shivange, A. V.; Knox, H. J.; Campello, H. R.; Wang, J. H.; Dougherty, D. A.; Looger, L. L.; Gallagher, T.; Rees, D. C.; Lester, H. A. Fluorescence Activation Mechanism and Imaging of Drug Permeation with New Sensors for Smoking-Cessation Ligands; preprint; Pharmacology and Toxicology, 2021. https://doi.org/10.1101/2021.10.04.463082.

(23) Chung, M.; Fortunato, G.; Radacsi, N. Wearable Flexible Sweat Sensors for Healthcare Monitoring: A Review. J. R. Soc. Interface. 2019, 16 (159), 20190217. https://doi.org/10.1098/rsif.2019.0217.

(24) Soares Nunes, L. A.; Mussavira, S.; Sukumaran Bindhu, O. Clinical and Diagnostic Utility of Saliva as a Non-Invasive Diagnostic Fluid: A Systematic Review. Biochem Med 2015, 25 (2), 177-192. https://doi.org/10.11613/BM.2015.018.

(25) Rivinoja, A.; Pujol, F. M.; Hassinen, A.; Kellokumpu, S. Golgi PH, Its Regulation and Roles in Human Disease. Annals of Medicine 2012, 44 (6), 542-554. https://doi.org/10.3109/07853890.2011.579150.

(26) De Duve, C.; De Barsy, T.; Poole, B.; Trouet, A.; Tulkens, P.; Van Hoof, F. Lysosomotropic Agents. Biochemical Pharmacology 1974, 23 (18), 2495-2531. https://doi.org/10.1016/0006-2952(74)90174-9.

(27) Abraham, A. D.; Casello, S. M.; Schattauer, S. S.; Wong, B. A.; Mizuno, G. O.; Mahe, K.; Tian, L.; Land, B. B.; Chavkin, C. Release of Endogenous Dynorphin Opioids in the Prefrontal Cortex Disrupts Cognition. Neuropsychopharmacol. 2021, 46 (13), 2330-2339. https://doi.org/10.1038/s41386-02101168-2.

(28) Long, A. S.; Zhang, A. D.; Meyer, C. E.; Egilman, A. C.; Ross, J. S.; Wallach, J. D. Evaluation of Trials Comparing Single-Enantiomer Drugs to Their Racemic Precursors: A Systematic Review. JAMA Netw Open 2021, 4 (5), e215731. https://doi.org/10.1001/jamanetworkopen.2021.5731.

(29) Fogaça, M. V.; Fukumoto, K.; Franklin, T.; Liu, R.-J.; Duman, C. H.; Vitolo, O. V.; Duman, R. S. NMethyl-D-Aspartate Receptor Antagonist d-Methadone Produces Rapid, MTORC1-Dependent Antidepressant Effects. Neuropsychopharmacol. 2019, 44 (13), 2230-2238. https://doi.org/10.1038/s41386-019-0501-x. 